\title{
Deontological and Utilitarian Responses to Sacrificial Dilemmas Predict Disapproval of Sin Stocks
}

Paweł Niszczota ${ }^{1, *}$, Michał Białek ${ }^{2}$, Paul Conway ${ }^{3}$

Accepted for publication in Social Psychology

${ }^{1}$ Poznań University of Economics and Business; Department of International Finance

${ }^{2}$ University of Wrocław; Institute of Psychology

${ }^{3}$ University of Portsmouth; Department of Psychology

* Corresponding author: Paweł Niszczota, Poznań University of Economics and Business, al. Niepodległości 10, 61-875, Poznań, Poland; pawel.niszczota@ue.poznan.pl;

ORCID: 0000-0002-4150-3646

Funding. This research was supported by grant 2018/31/D/HS4/01814 from the National Science Centre, Poland.

Open Practices. The studies have been pre-registered. The pre-registration documents, data and materials are available at:

https://osf.io/9yhq2/?view_only=c793ce2b8dd94ed5a4aeb6baa2bcac32.

\section{CRediT authorship contribution statement}

Pawel Niszczota: Conceptualization, Data curation, Formal analysis, Funding acquisition, Investigation, Methodology, Project administration, Resources, Software, Supervision, Validation, Visualization, Writing - original draft.

Michał Białek: Formal analysis, Methodology, Validation, Writing - review \& editing.

Paul Conway: Formal analysis, Investigation, Methodology, Validation, Writing - original draft.

\footnotetext{
Abstract

Investors sometimes invest in so-called 'sin' stocks that cause social harm as a byproduct of doing business (e.g., tobacco companies). Three studies examined whether people who reject harm and maximize outcomes in sacrificial dilemmas approve less of investing in sin (but not conventional) stocks. We employed process dissociation to assess harm-rejection (deontological) and outcome-maximization (utilitarian) response tendencies independently. Study $1(N=337)$ assessed moral approval of stocks: People scoring higher on either deontological or utilitarian response tendencies disapproved of investing in sin, but not conventional, stocks. Study $2(N=402)$ replicated this effect for willingness-to-invest in companies abandoning (vs. retaining) socially responsible policies. Study 3 ( $N=558)$
} 
confirmed earlier findings using more conservative measures. These findings clarify the psychology of morally-questionable investment decisions.

Keywords: moral psychology; moral dilemmas; process dissociation; sin stocks; socially responsible investment 


\section{Introduction}

Sin stocks are stocks issued by companies that engage in socially or morally objectionable activities, allowing investors to profit from problematic products (Hong \& Kacperczyk, 2009). Classic examples include alcohol, tobacco, and gambling, but amid growing environmental and social concern, this list is growing (Trinks \& Scholtens, 2017). Companies can also change policies to become more 'sinful,' such as withdrawing planned green investments or increasing 'dirty' projects. Recent cases illustrate the backlash companies can receive from 'sinful' policy changes (e.g., Zingales, 2018). Some people view investing in sin stocks as more unacceptable than others. To illustrate, $87 \%$ of millennials believe that corporations should be judged on more than their financial performance; millennials are also twice as likely to divest from sin stocks than older investors (The Economist, 2020). This led us to examine whether views of sin stocks partly reflect moral concerns as captured via other methodologies.

Specifically, we examined how people respond to sacrificial dilemmas where maximizing wellbeing requires causing harm. Such harm violates deontological ethics but upholds utilitarian ethics (Kant, 1785/1948; Mill, 1861/2016), so judgments can be described as consistent with deontology or utilitarianism. That said, the psychology giving rise to sacrificial judgments rarely reflects adherence to philosophical ideals, and instead reflects a complex mixture of processes. Most famously, Greene (2007) argued for a dual-process model where deontological judgments primarily reflect affective aversion to harm and utilitarian judgments primarily reflect cognitive evaluations of outcomes, though other processes may also be involved (Conway et al., 2018). Dilemmas have been criticized for a lack of external and predictive validity (Bauman et al., 2014), raising questions about whether sacrificial dilemma responses meaningfully predict important realistic decisions like investments. Nonetheless, we suggest that dilemma responding can provide a window into the (moral) psychology of investors.

\subsection{Predicting Sin Stock Investment from Sacrificial Dilemma Judgments}

Several studies show that morally relevant traits can influence investment decisions. For example, Gibson et al. (2021) found that investors scoring higher in prosocial social value orientation derive greater utility from investing in companies whose CEOs do not engage in morally objectionable 'earnings management' practices. Chew and Li (2021) found that altruistic behavior in the Dictator Game predicted aversion towards sin stocks. Finally, investment fund managers that support the Democratic Party were less likely than others to hold socially irresponsible stocks in their portfolios: this finding held for operationalizations based on both controversial products and exploitative labor practices, that Democratic voters find especially aversive (Hong \& Kostovetsky, 2012). However, it remains unclear whether sacrificial dilemma response likewise influence investment choices.

It is intuitive to expect that deontological responding should predict disapproval of $\sin$ stocks. Deontological responding is theorized to primarily reflect an affective reaction to causing harm, and is uniquely tied to constructs like empathic concern, aversion to harm, and belief in absolute moral rules (e.g., Reynolds \& Conway, 2018). Sin stock companies cause harm in either absolute (e.g., by producing tobacco) or relative terms (e.g., by abandoning socially beneficial policies), which violates ethical principles and is emotionally upsetting, suggesting that people drawn to deontological principles will reject such investments.

However, predictions for utilitarian responding are less clear. Utilitarian responding is theorized to primarily reflect a cognitive evaluation of overall outcomes, and is uniquely related to measures of cognitive processing (Byrd \& Conway, 2019; Patil et al., 2021). However, debates continue over the degree to which utilitarian dilemma responding reflects 
moral concern for others. Some theorists have argued that utilitarian responses reflect a combination of mere amoral pragmatic reasoning and antisocial tendencies to accept harm for immoral ends, such as psychopathy (e.g., Kahane et al., 2015). Such a perspective suggests that utilitarian responses should at best predict indifference to sin stocks, if not increased approval due to either: (a) the reasonable assumption that sin stocks provide higher rates of return (Hong and Kacperczyk, 2009), or (b) embracing the antisocial elements of sin stocks (e.g., psychopathy predicts approval of gambling; Jones, 2013). If utilitarian responding indeed reflects antisocial or amoral tendencies, it may predict overlooking the harm sin stocks cause relative to the social benefits of sinful companies such as taxes, employment, and contribution to the economy (e.g., paying suppliers of raw materials).

Some theorists have furthermore argued for a subjective utilitarian model of sacrificial decision-making, where estimates of general utility are biased in favor of personal gain (e.g., Cohen \& Ahn, 2016; Engelmann \& Waldmann, 2022) — suggesting that people who endorse utilitarian responding may invest more in sin stocks if they believe such stocks will be personally profitable. Indeed, Hong and Kacperczyk (2009), showed that investment in morally controversial companies produced higher expected returns than other companies. Hence, investors likely perceive rejecting sin stock investments as involving a personal cost (e.g., Bénabou \& Tirole, 2011). If so, then people who endorse utilitarian decisions may logically and pragmatically evaluate sin stocks in a biased manner consistent with personal interest - demonstrating at least no systematic tendency to reject sin stock investments, or even an increased willingness to make such investments.

If utilitarian responding indeed reflects pragmatism, subjectivity, or antisociality, then increased utilitarian responding may well predict increased acceptance of sin stock investment - after all such investment may be conceptualized as sacrificing some people or principles in the pragmatic pursuit of higher profit. Indeed, conventional measures of dilemma responding typically treat deontological and utilitarian responding as opposites on a single continuum, so conventional approaches would suggest that people most willing to invest in sin stocks would score either low in deontological responding and/or high in utilitarian responding - which in conventional responding amount to the same thing.

\subsection{Disentangling Deontological and Utilitarian Responses}

However, classic approaches have been challenged by modeling approaches - as we employ in the current work (process dissociation) - that independently estimate the degree to which people reject causing harm (deontological inclinations) and strive to maximize outcomes (utilitarian inclinations) (Conway \& Gawronski, 2013; Gawronski et al., 2017). Such approaches cast doubt on the arguments that utilitarian responding reflects mere pragmatism or antisociality, instead reflecting to some degree genuine concern for minimizing harm in aggregate (e.g., Conway et al., 2018).

In particular, modelling approaches demonstrate that people who care about morality tend to score high on both response tendencies, whereas people who care less score low on both. For example, people high in moral identity, moral conviction about harm, and concern for others both want to avoid causing harm and to maximize outcomes, whereas people high in psychopathy and egoism are relatively unconcerned about either (e.g., Conway et al., 2018; Körner et al., 2020; see also Białek \& De Neys, 2017; Mata, 2019). Although these findings challenge the argument that utilitarian responding reflects antisociality, they nonetheless find some support for a unique relationship between deontological responding and affective reactions to harm and utilitarian responding and cognitive processing, albeit with more complexity than the original dual process model (e.g., Byrd \& Conway, 2019; Gawronski et al., 2017; Patil et al., 2021; Reynolds \& Conway, 2018). 
Our analytical approach enables us to also learn more about how people perceive morally controversial companies, as judgments made by people with different moral inclinations can reveal whether they weigh their harm against their benefits. As we explained, deontological inclinations should be predictive of disapproval of sin stocks, regardless of the benefits that they provide to society. In contrast, when considering whether an investment in sin stocks is morally acceptable or not, people with high utilitarian inclinations should consider not only the harm that the products sold by the company can cause, but also the societal benefits of the company's operation. These include taxes that the company pays and the employment it provides, either directly, or via other companies (e.g., suppliers of raw materials used to make the controversial products). If the harms of sin stocks exceed the benefits, people with utilitarian inclinations should disapprove of investment in sin stocks.

The presence or absence of an interaction effect between deontological and utilitarian inclinations will be much more revealing. If both deontological and utilitarian inclinations predict sin stock disapproval, but there is no interaction between these inclinations on disapproval, this would suggest that people perceive morally controversial companies to be purely detrimental to society: the benefits of the sin stock would be irrelevant relative to the harm, leaving no reason for people with a utilitarian inclination to judge them less harshly. If the benefits of sin stocks are not considered in the judgment of sin stocks, an increased deontological inclination should have a similar effect for people with a high or low utilitarian inclination. If, however, a higher utilitarian sensitivity will cause a dampening of the condemnation of sin stocks, this would suggest that people do in fact weigh the societal harms and benefits of sin stocks.

\subsection{The Current Work}

In the current work, we employed process dissociation to independently assess deontological and utilitarian responding in sacrificial dilemmas and used these measures to predict sin stock acceptability and investment decisions. We made the straightforward prediction that deontological responding would predict reduced investment in sin stocks, but not regular stocks.

However, inconsistent with views of utilitarian responses as reflecting amoral or antisocial tendencies, we also expected that utilitarian responses would predict reduced investment in sin stocks, but not regular stocks. ${ }^{1}$ Furthermore, consistent with the theory argument that people who especially care about morality strive to balance deontological and utilitarian concerns--i.e., experience a genuine dilemma--we predicted a three-way interaction, such that people scoring low in both response tendencies would particularly approve of sin relative to conventional stocks. The presence of a three-way interaction would also be consistent with a dampening effect of having a high utilitarian sensitivity if one also has a high deontological sensitivity.

We anticipated these findings would hold above and beyond control measures of gender, risk tolerance, and investment knowledge. We tested these hypotheses in three studies involving two operationalizations: in Studies 1 and 3, sin stocks operated in morally controversial versus uncontroversial industries; in Study 2, sin stocks abandoned a socially responsible policy whereas non-sin stocks continued the policy.

All studies were approved by an institutional ethics committee and adhered to appropriate guidelines. Data and materials are available at:

\footnotetext{
${ }^{1}$ Our original prediction for utilitarian responding was different but this was the prediction from Study 2 forward.
} 
https://osf.io/9yhq2/?view only=c793ce2b8dd94ed5a4aeb6baa2bcac32. All measures, manipulations and exclusions are disclosed.

\section{Study 1}

\subsection{Method}

\subsubsection{Participants}

We recruited 501 American participants via Mechanical Turk (MTurk) who had completed at least 1000 tasks with a 95\% approval rate. Sample size was determined before any data analysis. To control for the quality of responses, we preregistered to exclude all participants who failed to recognize which dilemma was not used. We estimated that $\sim 20 \%$ would do so, leaving $\sim 400$, providing $\sim 95 \%$ power to detect an effect of $f^{2}=.033$, and $80 \%$ power to detect a $f^{2}=.02$ (small) effect. Ultimately, 164 participants failed the check, leaving $337\left(M_{\text {age }}=40.5, S D=12.2 ; 149\right.$ female and 188 male $)$. The attrition rate was $7.6 \% ; 27 \%$ of this attrition happened while rating the moral dilemmas.

\subsubsection{Materials and procedure}

Participants judged whether it would be morally appropriate to invest in each stock on a scale from 1 (not at all) to 7 (completely). We averaged ratings for seven sin stocks (e.g., fur and gambling industries) and seven conventional stocks (e.g., water utilities and semiconductor producers). We used the same sin stocks as a prior study (Niszczota \& Białek, 2021), reflecting a subset of 14 controversial stocks from Trinks and Scholtens (2017). Note that all participants rated both sin and conventional stocks, i.e. stock type was a withinsubjects factor.

Next, participants completed the process dissociation moral dilemma battery (Conway $\&$ Gawronski, 2013). This battery includes 10 moral dilemmas, each with an incongruent and congruent version, presented in a fixed random order. Incongruent dilemmas parallel conventional sacrificial dilemmas (e.g., Koenigs et al., 2007): they entail causing a harmful act (violating deontological proscriptions against harm) that nonetheless results in greater overall outcomes (upholding utilitarian prescriptions to maximize overall well-being) - for example, killing a baby to save a village from death. Congruent dilemmas describe an identical harmful action where the utility is reduced - for example, killing a baby to save a village from hard labor.

By submitting responses to a processing tree and following the six formulae described by Conway and Gawronski, we computed two parameters: the deontological (D) parameter, reflecting the tendency to systematically reject all actions that directly cause harm regardless of the outcomes they produce, and the utilitarian $(U)$ parameter, reflecting a sensitivity to outcomes such that participants are more willing to endorse a harmful action that clearly maximizes outcomes than an equivalent action that does not necessarily do so. Finally, to additionally test for possible confounding factors, we assessed gender, age, risk tolerance, subjective investment knowledge, and objective basic investment knowledge via a six-item test (Dohmen et al., 2011; Niszczota \& Białek, 2021; van Rooij et al., 2011). We preregistered the study at: https://aspredicted.org/HAD_UOH.

\subsection{Results}

We performed regressions on the moral approbation of stocks, with the following predictors: stock type (sin vs conventional), standardized deontological parameter, standardized utilitarian parameter, the two-way interaction between the parameters and between each parameter and condition, the three-way interaction between the parameters and condition, and control variables: participants gender, risk tolerance, and objective investment knowledge (see Table 1). Results are comparable without control variables. 
Table 1. People scoring higher on both deontological and utilitarian response tendencies in sacrificial dilemmas rated investing in sin versus conventional stocks as less morally appropriate, Studies 1-3.

\begin{tabular}{|c|c|c|c|c|c|c|c|c|c|}
\hline & \multicolumn{9}{|c|}{ Moral appropriateness of investing in stocks } \\
\hline & \multicolumn{3}{|c|}{ Study 1} & \multicolumn{3}{|c|}{ Study 2} & \multicolumn{3}{|l|}{ Study 3} \\
\hline & $b[95 \% C I]$ & $S E$ & $p$ & $b[95 \% C I]$ & $S E$ & $p$ & $b[95 \% C I]$ & $S E$ & $p$ \\
\hline (Intercept) & $5.68^{* * *}[5.20,6.17]$ & 0.25 & $<.001$ & $5.70^{* * *}[5.27,6.12]$ & 0.22 & $<.001$ & $6.26^{* * *}[4.94,5.59]$ & 0.17 & $<.001$ \\
\hline Deontological PD Parameter $(D)$ & $-0.01[-0.18,0.16]$ & 0.08 & 0.899 & $0.12[-0.02,0.26]$ & 0.07 & 0.086 & $0.09[-0.02,0.20]$ & 0.06 & 0.105 \\
\hline Utilitarian PD Parameter $(U)$ & $0.07[-0.09,0.23]$ & 0.08 & 0.366 & $0.20^{* *}[0.06,0.34]$ & 0.07 & 0.004 & $0.22 * * *[0.11,0.32]$ & 0.05 & $<.001$ \\
\hline Stock type $(0=$ conventional, $1=\sin )$ & $-2.73^{* * *}[-2.92,-2.55]$ & 0.09 & $<.001$ & $-2.86^{* * *}[-3.01,-2.71]$ & 0.08 & $<.001$ & $-2.19^{* * *}[-2.31,-2.07]$ & 0.06 & $<.001$ \\
\hline Gender $(0=m, 1=f)$ & $-0.19[-0.40,0.02]$ & 0.11 & 0.071 & $-0.27^{* *}[-0.46,-0.08]$ & 0.10 & 0.005 & $-0.04[-0.18,0.11]$ & 0.08 & 0.630 \\
\hline Risk tolerance & $0.02[-0.02,0.06]$ & 0.02 & 0.297 & $0.04^{*}[0.00,0.08]$ & 0.02 & 0.043 & $0.06^{* * *}[0.03,0.09]$ & 0.01 & $<.001$ \\
\hline Investment knowledge & $0.09^{*}[0.00,0.18]$ & 0.05 & 0.044 & $-0.00[-0.08,0.07]$ & 0.04 & 0.965 & $0.02[-0.04,0.08]$ & 0.03 & 0.527 \\
\hline$D \times U$ & $-0.13[-0.29,0.03]$ & 0.08 & 0.111 & $-0.02[-0.16,0.11]$ & 0.07 & 0.725 & $0.00[-0.10,0.11]$ & 0.05 & 0.98 \\
\hline$D \times$ stock type & $-0.47^{* * *}[-0.68,-0.26]$ & 0.11 & $<.001$ & $-0.55^{* * *}[-0.71,-0.38]$ & 0.08 & $<.001$ & $-0.77 * * *[-0.90,-0.64]$ & 0.07 & $<.001$ \\
\hline$U \times$ stock type & $-0.27^{* *}[-0.47,-0.07]$ & 0.10 & 0.009 & $-0.22^{* *}[-0.38,-0.06]$ & 0.08 & 0.008 & $-0.50 * * *[-0.62,-0.38]$ & 0.06 & $<.001$ \\
\hline$D \times U \times$ stock type & $0.40^{* * *}[0.19,0.61]$ & 0.11 & $<.001$ & $0.19^{*}[0.03,0.35]$ & 0.08 & 0.023 & $0.21 * *[0.08,0.34]$ & 0.07 & 0.001 \\
\hline \multicolumn{10}{|l|}{ Random Effects } \\
\hline$\sigma^{2}$ & \multicolumn{3}{|l|}{1.29} & \multicolumn{3}{|l|}{0.99} & \multicolumn{3}{|l|}{0.93} \\
\hline$\tau_{00 \text { id }}$ & \multicolumn{3}{|l|}{0.2} & \multicolumn{3}{|l|}{0.33} & \multicolumn{3}{|l|}{0.28} \\
\hline $\mathrm{ICC}$ & \multicolumn{3}{|l|}{0.13} & \multicolumn{3}{|l|}{0.25} & \multicolumn{3}{|l|}{0.23} \\
\hline$N_{\text {id }}$ & \multicolumn{3}{|l|}{337} & \multicolumn{3}{|l|}{402} & \multicolumn{3}{|l|}{558} \\
\hline Observations & \multicolumn{3}{|c|}{$674(2 \times 337)$} & \multicolumn{3}{|c|}{$804(2 \times 402)$} & \multicolumn{3}{|c|}{$1116(2 \times 558)$} \\
\hline Marginal $\mathrm{R}^{2} /$ Conditional $\mathrm{R}^{2}$ & \multicolumn{3}{|c|}{$0.592 / 0.647$} & \multicolumn{3}{|c|}{$0.646 / 0.734$} & \multicolumn{3}{|c|}{$0.603 / 0.694$} \\
\hline
\end{tabular}

Note: PD parameters are standardized. For moral appropriateness ratings there are two observations per participant, as each person assessed both sin and conventional stocks. Computations were performed using the $l m e r$ function from package lmerTest (Kuznetsova et al., 2017), which alters the function originally from the $l m e 4$ package in $R$ (Bates et al., 2015). * $p<.05 * * p<.01 * * * p<.001$ 
The stock type predictor confirmed that overall, participants rated investing in sin stocks as significantly less morally appropriate than investing in non-sin stocks, as expected ( $\left.M_{\text {conventional }}=6.14, S D=1.21, M_{\sin }=3.29, S D=1.32, d=2.26[2.06,2.45]\right)$. Coefficients for variables $D$ and $U$ indicate that neither deontological nor utilitarian inclinations predicted approval of investing in conventional (non-sin) stocks. Such stocks served as a baseline in the subsequent regression.

As predicted, the coefficient for the $D \times$ stock type interaction was significant, showing that people who rejected sacrificial harm morally disapproved of investing in sin stocks. Likewise, the $U \times$ stock type interaction was significant, showing that people who aimed to maximize overall outcomes in sacrificial dilemmas also morally disapproved of investing in sin stocks. There was no significant interaction between $D$ and $U$, but the threeway interaction between $D \times U \times$ stock type was significant, showing that the combination of low $D$ and $U$ scores led to the most lenient judgments of sin stocks. In Figure 1, we illustrate how the deontology and utilitarian parameters interact with approval of sin and conventional stocks. The lines indicating predicted moral approval for high $(+2 S D)$ and low $(-2 S D)$ utilitarian PD parameters cross, indicating an interaction. This figure illustrates how the pattern was primarily driven by especially high sin stock moral approval ratings for people low in both deontological and utilitarian concerns; moral disapproval of sin stocks was slightly tempered for people high in both tendencies, consistent with high $U$ dampening the effect of a high $D$ on sin stock ratings. We replicated this analysis for each individual sin stock (see Electronic Supplementary Material 2 Figure S1), which shows a similar (crossing) pattern for all stocks bar those that are involved in abortion/abortifacients. 
A Moral appropriateness: Study 1

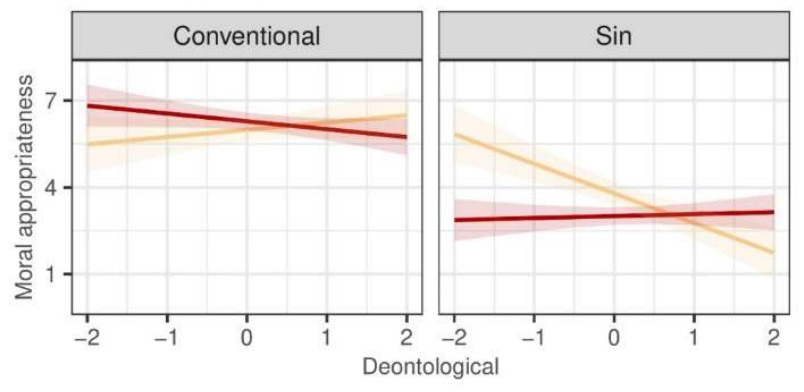

Study 2

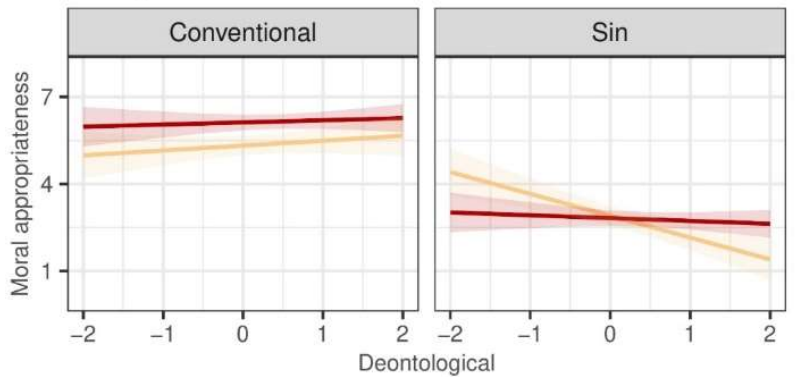

Study 3

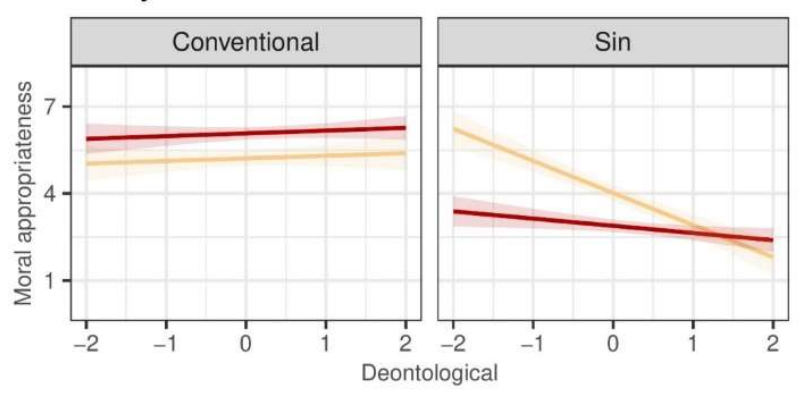

Utilitarian
B Moral appropriateness

Studies 1-3 pooled

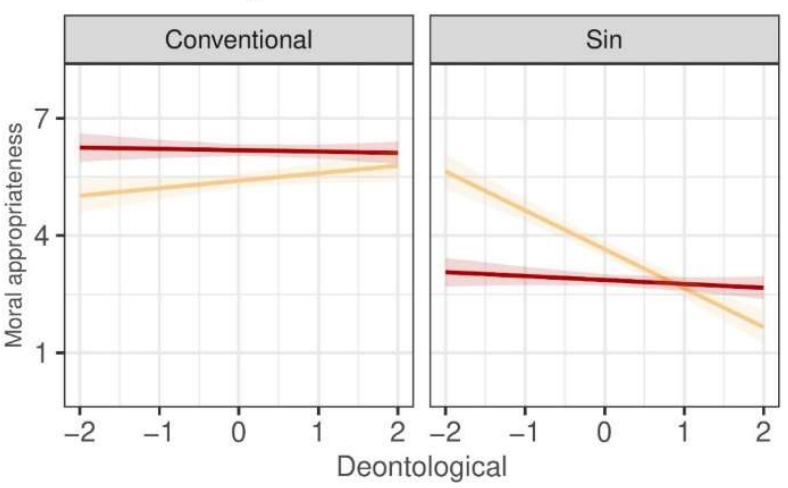

Utilitarian $\quad-2 \square 2$

C Likelihood of investing

Study 2

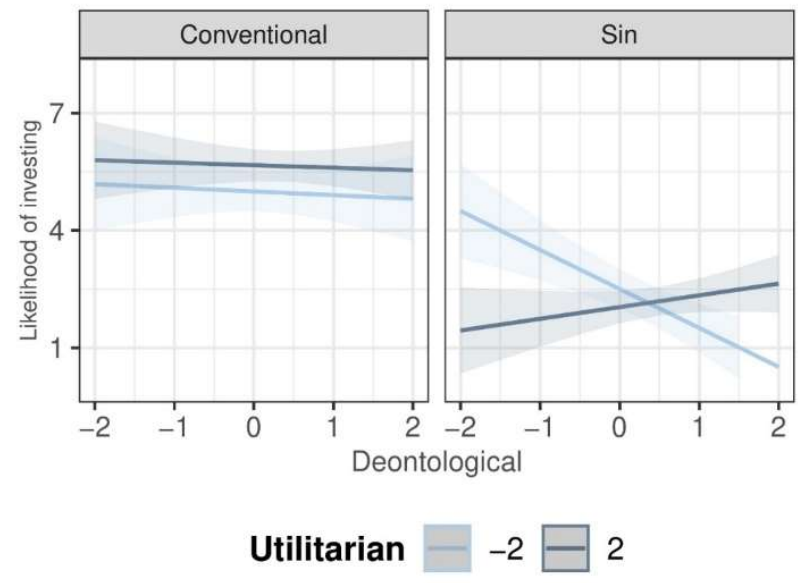

Figure 1. The interaction between standardized deontological and utilitarian response tendencies in sacrificial dilemmas and moral evaluations (panel A: Studies 1-3 separately; panel B: Studies 1-3 pooled) and willingness to invest (panel $\mathbf{C}$ ) in sin stocks, but generally not conventional stocks. Effects plotted for the low $(-2 S D)$ and high $(+2 S D)$ utilitarian inclinations. Error bars represent $95 \%$ confidence intervals. 


\subsection{Discussion}

People scoring higher on either deontological and utilitarian response tendencies reported reduced moral approval of sin but not conventional stocks. In other words, both people who refused to directly inflict sacrificial harm and people who were sensitive to the outcomes of sacrificial action reported that investing in harmful stocks is less morally acceptable; on the other hand, people relatively unconcerned about causing harm or maximizing outcomes reported greater approval of investing in sin stocks.

Although we originally predicted this pattern only for deontological, not utilitarian, response tendencies, in retrospect, this pattern fits with a growing literature showing that people especially concerned about morality tend to be sensitive to both deontological and utilitarian considerations (e.g., Conway et al., 2018). Past work showing this pattern has assessed individual differences such as moral identity, moral conviction about harm, psychopathy, and egoism. The current findings extend this pattern to moral approval of investment decisions. However, important questions remain, including whether this pattern would replicate in a new sample, whether it would predict willingness to invest rather than just moral approval, and whether it would emerge using another operationalization of sin versus non-sin stocks. Hence, we conducted a second preregistered study.

\section{Study 2}

In Study 1, we operationalized sin stocks as companies operating in morally controversial industries, which confounds perceptions of sinfulness with other aspects of the investment (e.g., participants might assume that sin stocks are more profitable than non-sin stocks). In Study 2, we operationalized sin stocks as a company that abandons (versus retains) a corporate social responsibility policy to maximize profits, allowing greater experimental control. Corporate social responsibility policies provide benefits to society, such as reduced pollution, increased safety, or less deception. Eliminating such policies to maximize profit essentially amount to a 'sinful' switch away from operations that benefit society to operations that damage society at a selfish benefit to the organization itself.

We anticipated replicating the Study 1 pattern that both the deontological parameter and the interaction between the deontological and utilitarian parameter predict willingness to invest in sin stocks but not conventional stocks. We also assessed the moral approval of sin and non-sin stocks from Study 1. See preregistration at: https://aspredicted.org/GXX_DPZ.

\subsection{Method}

\subsubsection{Participants}

We recruited 602 American MTurk workers. Sample size was determined before any data analysis. Based on the same attention check as Study 1, we excluded 200 people, resulting in a final sample of 402 participants $\left(M_{\mathrm{age}}=37.31, S D=10.85,183\right.$ female, 219 male $)$. This provided us $\sim 95 \%$ power to detect an effect of $f^{2}=.033$ (and $80 \%$ for an effect of $f^{2}=.02$ ). The attrition rate was $5.8 \% ; 32 \%$ of this attrition happened while rating the moral dilemmas.

\subsubsection{Materials and procedure}

This experiment replicated Study 1 and extended it by additionally introducing two scenarios aimed to test willingness to invest in a company that abandons corporate social responsibility policies to maximize profits (versus a company that will continue their current policies). Firstly, participants completed the moral appropriateness of investing in the seven sin and seven conventional stocks on the same 1-7 scale as in Study 1. We took the average of these ratings. Although we did not include this measure in the preregistration, one of our objectives was to replicate the patterns observed in Study 1. 
Secondly, we presented participants with two scenarios, either in the sin or non-sin version (see Electronic Supplementary Material 1). The order of presentation was counterbalanced. The second scenario was adapted from Bhattacharjee et al. (2017). Participants rated the likelihood that they would invest in the two companies on scales from 1 (extremely unlikely) to 7 (extremely likely). We took the average of these ratings to construct the dependent variable.

Finally, participants completed the same process dissociation moral dilemma battery as in Study 1, and completed the same measures of demographics, risk tolerance, and investment knowledge.

\subsection{Results}

\subsubsection{Moral appropriateness}

Participants rated the moral appropriateness of investing in the same sin and conventional stocks from Study 1 (see Figure 1; in Electronic Supplementary Material 2 Figures S1-S2 we present ratings individually for each of the sin and conventional stocks). We also employed the same, preregistered analysis (Table 1). Once again, stock type was significant, showing that, overall, participants rated investing in sin stocks less morally appropriate than conventional stocks $\left(M_{\text {conventional }}=5.81, S D=1.14, M_{\sin }=2.80, S D=1.26, d=2.51\right.$ $[2.32,2.69])$. We replicated the finding that both the $D \times$ stock type and $U \times$ stock type interactions were significant, showing that people who rejected sacrificial harm and maximized overall outcomes each reported lower moral approval of investing in sin stocks. In addition, we replicated the three-way interaction between parameter and stock type, showing that people scoring low on both parameters showed the most approval for sin stocks. There was, yet again, evidence of a dampening effect of having a high utilitarian inclination in the presence of a high deontological inclination, consistent with the notion that people with a utilitarian sensitivity weigh the societal harms of sin stocks against the societal benefits.

\subsubsection{Willingness to invest}

This analysis reflected only the two newly created scenarios. First, we confirmed that participants reported lower willingness to invest in sin than conventional stocks ( $M_{\text {conventional }}=5.35, S D=1.25, M_{\sin }=2.24, S D=1.34, d=2.41[2.15,2.67]$ ), suggesting our manipulation was successful. Next, we employed the same regression analysis as in Study 1, and examined whether sacrificial dilemma responses predicted willingness to invest in the sin and non-sin stocks (Table 2).

The same $D \times$ stock type and $U \times$ stock type interactions that were observed in Study 1 also emerged in Study 2, but did not reach conventional levels of significance when applying preregistered exclusions $(p s<.07)$. In a re-analysis of the full sample $(N=602)$, both of these interactions were significant. Moreover, replicating Study 1, the expected three-way interaction between parameter and stock type was significant, regardless of whether the exclusion criteria was applied or not. As in Study 1, this pattern was primarily driven by especially high sin stock moral approval ratings for people low in both deontological and utilitarian concerns; willingness to invest in sin stocks was slightly tempered for people high in both tendencies, consistent with a dampening effect (see Figure 1).

Overall, despite using different experimental materials and dependent measures, the pattern appeared similar to (albeit smaller than) preregistered predictions based on Study 1 . Notably, Study 2 manipulated sin stocks using a between-subjects design, somewhat reducing statistical power. 
Table 2. People scoring higher on both deontological and utilitarian response tendencies in sacrificial dilemmas report lower likelihood of investing in sin stocks, Study 2.

\begin{tabular}{|c|c|c|c|c|c|c|}
\hline & \multicolumn{6}{|c|}{ Likelihood of investing in stocks } \\
\hline & \multicolumn{3}{|c|}{ Preregistered exclusions } & \multicolumn{3}{|c|}{ No exclusions } \\
\hline & $b[95 \% C I]$ & $S E$ & $p$ & $b[95 \% C I]$ & $S E$ & $p$ \\
\hline (Intercept) & $6.04^{* * *}[5.45,6.62]$ & 0.30 & $<.001$ & $5.70^{* * *}[5.23,6.18]$ & 0.24 & $<.001$ \\
\hline Deontological PD Parameter $(D)$ & $-0.08[-0.28,0.12]$ & 0.10 & .436 & $0.04[-0.11,0.19]$ & 0.08 & .587 \\
\hline Utilitarian PD Parameter $(U)$ & $0.17[-0.04,0.38]$ & 0.11 & .115 & $0.26^{* *}[0.09,0.42]$ & 0.08 & .002 \\
\hline Stock type $(0=$ conventional, $1=\sin )$ & $-3.06^{* * *}[-3.32,-2.80]$ & 0.13 & $<.001$ & $-2.66^{* * *}[-2.87,-2.44]$ & 0.11 & $<.001$ \\
\hline Gender $(0=m, 1=f)$ & $0.08[-0.18,0.34]$ & 0.13 & .552 & $0.04[-0.18,0.25]$ & 0.11 & .746 \\
\hline Risk tolerance & $0.05[-0.00,0.10]$ & 0.03 & .071 & $0.12^{* * *}[0.08,0.16]$ & 0.02 & $<.001$ \\
\hline Investment knowledge & $-0.20^{* * *}[-0.30,-0.10]$ & 0.05 & $<.001$ & $-0.21^{* * *}[-0.29,-0.13]$ & 0.04 & $<.001$ \\
\hline$D \times U$ & $0.01[-0.20,0.21]$ & 0.10 & .942 & $-0.04[-0.19,0.10]$ & 0.07 & .552 \\
\hline$D \times$ stock type & $-0.27^{\dagger}[-0.56,0.02]$ & 0.15 & .069 & $-0.32^{* *}[-0.54,-0.11]$ & 0.11 & .003 \\
\hline$U \times$ stock type & $-0.28^{\dagger}[-0.57,0.01]$ & 0.15 & .055 & $-0.64^{* * *}[-0.85,-0.42]$ & 0.11 & $<.001$ \\
\hline$D \times U \times$ stock type & $0.32^{*}[0.03,0.60]$ & 0.15 & .030 & $0.33^{* *}[0.12,0.54]$ & 0.11 & .002 \\
\hline Observations & 402 & & & 602 & & \\
\hline $\mathrm{R}^{2}$ adjusted & 0.632 & & & 0.570 & & \\
\hline
\end{tabular}

Note: The table presents $O L S$ regressions. PD parameters are standardized. Stock type was a between-subjects factor.

$\dagger p<.07,{ }^{*} p<.05, * * p<.01, * * * p<.001$ 


\subsection{Discussion}

The results of Study 2 largely replicated and extended those of Study 1, meshing with preregistered predictions, using a different manipulation of sin stocks - companies abandoning corporate social responsibility policies. People scoring high on both deontological and utilitarian inclinations in sacrificial dilemmas - who both seek to avoid causing harm and who seek to maximize overall outcomes - reported lower willingness to invest in sin (but not conventional) stocks, and additionally rated doing so as less morally acceptable. Moreover, for moral approval the two-way and three-way interactions from Study 1 both replicated. Although for willingness to invest the two-way interactions between $D$ and stock type and $U$ and stock type did not reach conventional levels of significance, these effects became significant in the full-sample analysis, and the three-way interaction between parameters and stock type remained significant in both analyses. Therefore, we suggest these findings largely corroborate those of Study 1.

\section{Study 3}

Perhaps our selection of conventional industries was not representative of typical (neutral) companies on the stock market. Many were unequivocally beneficial to society, such as water utility companies or companies involved in the transportation of goods. To address this issue, in Study 3 we used an alternative list of conventional industries with a less clear societal impact, such as application software, paper packaging, and research and consulting services. ${ }^{2}$

We also addressed two potential shortcomings of our prior studies. Firstly, we added a buffer task (a brief personality questionnaire; Gosling et al., 2003) to minimize the potential impact of rating companies prior to moral dilemmas. Secondly, we reduced the difficulty of the attention check by using an alternative one, that related to industries and not dilemmas. We preregistered the study at: https://aspredicted.org/PCP VKM.

\subsection{Method}

\subsubsection{Participants}

We recruited 750 American MTurk workers who had completed at least 1000 tasks. Sample size was determined before any data analysis: it was increased, relative to Study 1, as we expected effects to be smaller, given that the dissimilarity between sin and conventional stocks was reduced by design. Due to a relatively high exclusion rate in Studies 1 and 2, we increased the minimum approval rate from $95 \%$ to $98 \%$ and used an alternative attention check. We estimated that $20 \%$ would nonetheless fail, leaving $\sim 600$, providing $\sim 95 \%$ power to detect an effect of $f^{2}=0.022$. Ultimately, 192 participants failed the check, leaving $558\left(M_{\mathrm{age}}=39.3, S D=11.4 ; 245\right.$ female, 308 male, 5 non-binary or undisclosed). The attrition rate was $8.6 \% ; 12 \%$ of this attrition happened while rating the moral dilemmas.

\subsubsection{Materials and procedure}

Similar to Study 1, participants rated both sin and conventional stocks, i.e. stock type was a within-subjects factor. Participants judged whether it would be morally appropriate to invest in each stock on a scale from 1 (not at all) to 7 (completely). We averaged ratings for seven sin stocks and seven alternative conventional stocks (see Electronic Supplementary Material 1).

\footnotetext{
${ }^{2}$ We conducted a pilot study $(N=131)$ to compare the original and alternative set of sin stocks. All alternative conventional stocks had lower ratings than each of the original conventional stocks, with one exception. See Electronic Supplementary Material 2 Table S1 for details.
} 


\subsection{Results}

We used the same specifications as Study 1. Yet again, the stock type predictor confirmed that, as expected, participants rated investing in sin stocks as significantly less morally appropriate than investing in non-sin stocks overall $\left(M_{\text {conventional }}=5.72, S D=1.01, M_{\sin }=3.27, S D=1.26, d=1.98\right.$ $[1.84,2.12])$.

We replicated all prior findings concerning the effect of deontological and utilitarian inclinations on sin stock disapproval, notably two-way interactions between each parameter and stock type (see Table 1). The data again showed a three-way interaction, suggesting that people judge investing in morally controversial stocks most favorably when scoring low in both of these inclinations, but there is also a dampening effect of a high $U$ parameter if $D$ was also high.

\subsection{Discussion}

Study 3 replicated the key findings observed in Studies 1 and 2 using an alternative, more conservative set of conventional stocks. Again, we found two-way interactions such that people higher in deontological inclinations approved less of sin stock investment (relative to conventional stocks), as did people higher in utilitarian inclinations. Moreover, the three-way interaction suggests that people that score lowest on both inclinations approved the most of investing in sin stocks - again corroborating our argument that a combination of low deontological and utilitarian responding reflects the least moral concern. The study confirms the other consequence of the interaction effect: support for the notion that people that have a utilitarian inclination involve both societal harms and benefits in their assessments, given that deontological inclinations can be somewhat countered.

\section{General Discussion}

Across three studies, we examined whether responses to sacrificial moral dilemmas predicted moral approval of and willingness to invest in so-called 'sin' stocks - companies that might damage the public interest in pursuit of profit. We employed process dissociation to separately assess deontological inclinations - the tendency to reject causing sacrificial harm regardless of consequences - as well as utilitarian inclinations - the tendency to maximize outcomes regardless of causing harm (Conway \& Gawronski, 2013).

We found that both deontological and utilitarian response tendencies individually predicted reduced moral approval of investing in sin stocks. Moreover, we replicated a significant three-way interaction across all three studies, showing that effects are particularly driven by high acceptance of sin stocks by people low in both response tendencies. These findings held across multiple manipulations of sin and conventional stocks and while controlling for gender, risk tolerance, and investment knowledge.

The findings that deontological responding predicts reduced sin stock investment may seem straightforward, given that sin stocks violate ethical rules and cause harm, which are anathema to deontological concerns. However, the fact that utilitarian responding also predicted reduced sin stock investment is theoretically interesting. Not only does this pattern of results contradict the salient assumption that utilitarian considerations necessarily go against deontological consideration, it is also inconsistent with arguments that utilitarian responses reflect amoral pragmatic reasoning or antisocial acceptance of harm (e.g., Kahane et al., 2015). Instead, our results suggest that utilitarian sacrificial responses reflect moralized concern for the greater good. This finding suggests that people higher in utilitarian inclinations may adopt a pragmatic, intellectual view that encourages responsible investment activity in conventional stocks (Grinblatt et al., 2011; Kacperczyk et al., 2019). However, for people high in deontology, utilitarian concerns to some extent countered the deontological 
inclinations, rather than strengthened it. This serves as tentative evidence that people with utilitarian inclinations weigh the societal harms of sin stocks against their societal benefits.

The current findings show that people least concerned about morality are the most willing to invest in sin stocks, to their own financial benefit (Hong \& Kacperczyk, 2009). Yet, our work also suggests that morally controversial business activity will be opposed by people who care about morality. These findings align with a growing literature suggesting that peoples values and identity as moral beings influence business investments and other economic decisions (e.g., Bénabou \& Tirole, 2011). Such findings suggest that the increasing prevalence of people who care about moral concerns such as rejecting harm and maximizing outcomes in corporate board rooms and beyond (see, e.g., Niszczota \& Białek, 2021) may lead to further shifts in corporate policies and a proliferation of socially responsible investments. The latter include the decision to exclude coal stocks from portfolios (Pettifor, 2020), and the opposition towards companies that benefit from public misfortune, such as intrusive surveillance companies that thrive under pandemic conditions (Harari, 2020).

Moreover, the current findings held across two different sin stock manipulations and two different conventional stock manipulations. In particular, Study 2 used a subtle sin manipulation where a company was merely moving away from former prosocial policies, rather than clearly engaging in unethical behavior. Such patterns add to the growing literature showing that investor traits and moral beliefs influence stock investment choices operationalized in many different ways (e.g., Gibson et al., 2021; Hong \& Kostovetsky, 2012).

\subsection{Implications}

Our findings have implications for the moral decision-making literature. Some researchers have questioned the predictive utility of sacrificial dilemma studies (e.g., Bostyn et al., 2018; Oftedal et al., 2020). However, such work has relied exclusively on conventional relative dilemma analytic techniques, that treat deontological and utilitarian responses as opposites instead of assessing them independently. A host of research demonstrates that reliance on such relative analytic techniques tend to obscure underlying patterns due to suppression effects, because often deontological and utilitarian response tendencies jointly predict in the same direction, and this pattern is largely or completely wiped out for conventional analyses (e.g., Conway et al., 2018). Likewise, in the current work, deontological and utilitarian response tendencies jointly predict reduced approval of sin stocks, a pattern that conventional methods cannot detect. Hence, these findings contribute to a growing literature suggesting that sacrificial dilemmas capture psychological processes that do predict important realistic decisions - however, to find such effects researchers should employ modelling approaches than can disentangle response patterns invisible to traditional approaches.

\subsection{Limitations}

Like all studies, this work suffers from limitations. It is possible that the effects obtained pertain to the specific sin stocks examined here, although we operationalized sin using two techniques. Notably, companies dealing with abortion/abortifacients were largely immune to differences in moral inclinations. Moreover, investors might also deem a company "sinful" if it is helmed by dishonest CEOs (Gibson et al., 2021), or contravenes investors' political leanings. Future work might use other operationalizations and individual differences. These could more accurately account for the possibility that, for example, environmentalists may view polluting companies as sin stocks whereas people less concerned may not, and liberals may view different stocks as sinful than conservatives (Hong \& Kostovetsky, 2012).

Likewise, we did not investigate all possible sacrificial dilemmas. In particular, we focused on classic sacrificial dilemmas where causing harm maximizes outcomes. Some approaches include 
cases where action prevents harm but inflicts greater harm, which may entail somewhat different psychological processes (e.g., Gawronski et al., 2017; Hennig \& Hütter, 2020). It remains an open question whether response patterns to such dilemmas would likewise predict perceptions and decisions about sin stocks. Finally, sacrificial dilemmas have been criticized for a lack of external validity (e.g. Bauman et al., 2014), and it remains unclear the extent to which responses generalize to the real world.

Another limitation of the current work is that we did not counterbalance the order of some materials. All participants completed the stock task first, raising the possibility that completing this task influenced dilemma responses. That said, we manipulated stocks within-participants, so although this may influence mean level of dilemma responding it cannot explain individual differences in dilemma responding. Moreover, in Study 3 we introduced a filler task to increase the time between stock and dilemma tasks, allowing any priming influence to fade (e.g., Gillies \& Dozois, 2021), yet still replicated results.

Another limitation was that participants were not incentivized, which raises the possibility that results reflect mere "cheap talk," that will not correspond to actual investments. Perhaps, but past work suggests that a majority of ethical investors viewed unethical investments as reducing utility more than could be matched by higher expected returns--i.e., they were unwilling to sacrifice their moral convictions for money (Berry \& Yeung, 2013). Likewise, Bonnefon et al. (2019) gave participants the possibility to invest in neutral, antisocial, and prosocial companies (who increased or reduced charity donations), and found investment decisions were influenced by such externalities the company's operation causes.

Yet, an interesting question remains about tipping points--when does increased returns from unethical investment outweigh the social harm they do--particularly for people who lean towards utilitarian thinking. In the current work, both utilitarian and deontological responding predicted reduced approval of sin stocks, but we did not explicate that such stocks would provide higher returns. It seems plausible that deontological responding would continue predicting reduced sin stock investment even under such conditions; after all, in economic behavior studies, some participants remain "observationally deontological", i.e. never willing to accept money for causing harm (e.g., Bénabou et al., 2020). However, it remains possible that increasing the relative rate of return for sin over conventional stocks may reach a point where people higher in utilitarian responding start to evaluate such stocks more favorably. Such findings may align with subjective utility models where personal biases influence estimates of objective utility (Cohen \& Ahn, 2016), or with theory arguments that non-moral reasoning and antisociality can increase utilitarian responding (Kahane et al., 2015). Future work should test how resilient utilitarian responding is as a predictor as the relative rate of return for sin stocks increase.

\subsection{Directions for future research}

There may also be other cases where deontological and utilitarian responding diverge as predictors of sin stock investment. For example, if people that lean towards utilitarian responding are more sensitive to both costs and benefits, then increasing the salience of societal benefits of sin stocks (e.g., employment, taxes, government regulation) may reduce or reverse the predicted impact of utilitarian inclinations. Conversely, deontological responding should remain a steadfast predictor to the degree that such responses reflect concerns about moral rules and suffering victims.

To that end, we have focused on morally controversial stocks, but future work could extend research to study socially responsible investments. Disapproval of socially irresponsible stocks may not necessarily translate into an approval of socially responsible stocks: some evidence suggests these effects are non-symmetrical (Riedl \& Smeets, 2017, Chew \& Li, 2021). The perceived difference 
between sin versus conventional stocks may be larger than the difference between 'saint' and conventional stocks. Besides, some work suggests dilemma responses reflect concerns about minimizing harm rather than maximizing outcomes (Conway et al., 2018; Gawronski et al., 2017; Kahane et al., 2018). On the other hand, to the degree that increased deontological and utilitarian responding reflect mature moral concerns, they may predict approval of socially responsible investments. Future work should consider such possibilities.

\section{Conclusions}

In sum, across three studies we found that responses to sacrificial moral dilemmas predict moral approval of and willingness to invest in sin stocks. These findings help explain the processes involved in socially responsible investing.

\section{Electronic Supplementary Material}

ESM1. Stimuli (.pdf)

This document shows the list of morally controversial and conventional companies, and the battery of moral dilemmas (in an incongruent version and a congruent version).

ESM2. Supplementary figures and tables (.pdf)

This document shows predicted approval of stocks, separately for each industry/study, and results of a pilot study to Study 3 .

\section{References}

Bates, D., Mächler, M., Bolker, B. M., \& Walker, S. C. (2015). Fitting linear mixed-effects models using lme4. Journal of Statistical Software, 67(1). https://doi.org/10.18637/jss.v067.i01

Bauman, C. W., McGraw, A. P., Bartels, D. M., \& Warren, C. (2014). Revisiting External Validity: Concerns about Trolley Problems and Other Sacrificial Dilemmas in Moral Psychology. Social and Personality Psychology Compass, 8(9), 536-554. https://doi.org/10.1111/spc3.12131

Bénabou, R., Falk, A., Henkel, L., \& Tirole, J. (2020). Eliciting moral preferences: Theory and experiment. Princeton University Department of Economics Working Papers. https://economics.princeton.edu/working-papers/eliciting-moral-preferences/

Bénabou, R., \& Tirole, J. (2011). Identity, Morals, and Taboos: Beliefs as Assets. The Quarterly Journal of Economics, 126(2), 805-855. https://doi.org/10.1093/qje/qjr002

Berry, R. H., \& Yeung, F. (2013). Are Investors Willing to Sacrifice Cash for Morality? Journal of Business Ethics, 117(3), 477-492. https://doi.org/10.1007/s10551-012-1529-6

Bhattacharjee, A., Dana, J., \& Baron, J. (2017). Anti-profit beliefs: How people neglect the societal benefits of profit. Journal of Personality and Social Psychology, 113(5), 671-696. https://doi.org/10.1037/pspa0000093

Białek, M., \& De Neys, W. (2017). Dual processes and moral conflict: Evidence for deontological reasoners' intuitive utilitarian sensitivity. Judgment and Decision Making, 12(2), 148-167.

Bonnefon, J.-F., Landier, A., Sastry, P., \& Thesmar, D. (2019). Do Investors Care About Corporate Externalities? Experimental Evidence (SSRN Scholarly Paper ID 3458447). Social Science Research Network. https://papers.ssrn.com/abstract $=3458447$ 
Bostyn, D. H., Sevenhant, S., \& Roets, A. (2018). Of Mice, Men, and Trolleys: Hypothetical Judgment Versus Real-Life Behavior in Trolley-Style Moral Dilemmas: Psychological Science. https://doi.org/10.1177/0956797617752640

Byrd, N., \& Conway, P. (2019). Not all who ponder count costs: Arithmetic reflection predicts utilitarian tendencies, but logical reflection predicts both deontological and utilitarian tendencies. Cognition, 192, 103995. https://doi.org/10.1016/j.cognition.2019.06.007

Chew, S. H., \& Li, K. K. (2021). The Moral Investor: Sin Stock Aversion and Virtue Stock Affinity (SSRN Scholarly Paper ID 3773971). Social Science Research Network. https://doi.org/10.2139/ssrn.3773971

Cohen, D. J., \& Ahn, M. (2016). A subjective utilitarian theory of moral judgment. Journal of Experimental Psychology: General, 145(10), 1359-1381. https://doi.org/10.1037/xge0000210

Conway, P., \& Gawronski, B. (2013). Deontological and utilitarian inclinations in moral decision making: A process dissociation approach. Journal of Personality and Social Psychology, 104(2), 216-235. https://doi.org/10.1037/a0031021

Conway, P., Goldstein-Greenwood, J., Polacek, D., \& Greene, J. D. (2018). Sacrificial utilitarian judgments do reflect concern for the greater good: Clarification via process dissociation and the judgments of philosophers. Cognition, 179, 241-265. https://doi.org/10.1016/j.cognition.2018.04.018

Dohmen, T., Falk, A., Huffman, D., Sunde, U., Schupp, J., \& Wagner, G. G. (2011). Individual Risk Attitudes: Measurement, Determinants, and Behavioral Consequences. Journal of the European Economic Association, 9(3), 522-550. https://doi.org/10.1111/j.1542-4774.2011.01015.x

Engelmann, N., \& Waldmann, M. R. (2022). How to weigh lives. A computational model of moral judgment in multiple-outcome structures. Cognition, 218, 104910.

https://doi.org/10.1016/j.cognition.2021.104910

Gawronski, B., Armstrong, J., Conway, P., Friesdorf, R., \& Hütter, M. (2017). Consequences, norms, and generalized inaction in moral dilemmas: The CNI model of moral decision-making. Journal of Personality and Social Psychology, 113(3), 343-376. https://doi.org/10.1037/pspa0000086

Gibson, R., Sohn, M., Tanner, C., \& Wagner, A. F. (2021). Earnings Management and Managerial Honesty: The Investors' Perspectives (SSRN Scholarly Paper ID 2912795). Social Science Research Network. https://doi.org/10.2139/ssrn.2912795

Gillies, J. C. P., \& Dozois, D. J. A. (2021). How long do mood induction procedure (MIP) primes really last? Implications for cognitive vulnerability research. Journal of Affective Disorders, 292, 328-336. https://doi.org/10.1016/j.jad.2021.05.047

Gosling, S. D., Rentfrow, P. J., \& Swann Jr., W. B. (2003). A very brief measure of the Big-Five personality domains. Journal of Research in Personality, 37(6), 504-528. https://doi.org/10.1016/S0092-6566(03)00046-1

Greene, J. D. (2007). Why are VMPFC patients more utilitarian? A dual-process theory of moral judgment explains. Trends in Cognitive Sciences, 11(8), 322-323.

https://doi.org/10.1016/j.tics.2007.06.004

Grinblatt, M., Keloharju, M., \& Linnainmaa, J. (2011). IQ and Stock Market Participation. The Journal of Finance, 66(6), 2121-2164. https://doi.org/10.1111/j.1540-6261.2011.01701.x

Harari, Y. N. (2020, March 20). Yuval Noah Harari: The world after coronavirus. Financial Times. https://www.ft.com/content/19d90308-6858-11ea-a3c9-1fe6fedcca75 
Hennig, M., \& Hütter, M. (2020). Revisiting the divide between deontology and utilitarianism in moral dilemma judgment: A multinomial modeling approach. Journal of Personality and Social Psychology, 118(1), 22-56. https://doi.org/10.1037/pspa0000173

Hong, H., \& Kacperczyk, M. (2009). The price of sin: The effects of social norms on markets. Journal of Financial Economics, 93(1), 15-36. https://doi.org/10.1016/j.jfineco.2008.09.001

Hong, H., \& Kostovetsky, L. (2012). Red and blue investing: Values and finance. Journal of Financial Economics, 103(1), 1-19. https://doi.org/10.1016/j.jfineco.2011.01.006

Jones, D. N. (2013). What's mine is mine and what's yours is mine: The Dark Triad and gambling with your neighbor's money. Journal of Research in Personality, 47(5), 563-571.

https://doi.org/10.1016/j.jrp.2013.04.005

Kacperczyk, M., Nosal, J., \& Stevens, L. (2019). Investor sophistication and capital income inequality. Journal of Monetary Economics, 107, 18-31.

https://doi.org/10.1016/j.jmoneco.2018.11.002

Kahane, G., Everett, J. A. C., Earp, B. D., Caviola, L., Faber, N. S., Crockett, M. J., \& Savulescu, J. (2018). Beyond Sacrificial Harm: A Two-Dimensional Model of Utilitarian Psychology.

Psychological Review, 125(2), 131-164. https://doi.org/10.1037/rev0000093

Kahane, G., Everett, J. A. C., Earp, B. D., Farias, M., \& Savulescu, J. (2015). 'Utilitarian' judgments in sacrificial moral dilemmas do not reflect impartial concern for the greater good. Cognition, 134, 193-209. https://doi.org/10.1016/j.cognition.2014.10.005

Kant, I. (1948). Groundwork of the Metaphysic of Morals. HJ Paton. London: Hutchinson.

Koenigs, M., Young, L., Adolphs, R., Tranel, D., Cushman, F., Hauser, M., \& Damasio, A. (2007). Damage to the prefrontal cortex increases utilitarian moral judgements. Nature, 446(7138), 908. https://doi.org/10.1038/nature05631

Körner, A., Deutsch, R., \& Gawronski, B. (2020). Using the CNI Model to Investigate Individual Differences in Moral Dilemma Judgments. Personality and Social Psychology Bulletin, 0146167220907203. https://doi.org/10.1177/0146167220907203

Kuznetsova, A., Brockhoff, P. B., \& Christensen, R. H. (2017). lmerTest package: Tests in linear mixed effects models. Journal of Statistical Software, 82(13), 1-26.

Mata, A. (2019). Social metacognition in moral judgment: Decisional conflict promotes perspective taking. Journal of Personality and Social Psychology, 117(6), 1061-1082.

https://doi.org/10.1037/pspa0000170

Mill, J. S. (2016). Utilitarianism. In Seven Masterpieces of Philosophy (pp. 337-383). Routledge.

Niszczota, P., \& Białek, M. (2021). Women oppose sin stocks more than men do. Finance Research Letters, 41, 101803. https://doi.org/10.1016/j.frl.2020.101803

Oftedal, G., Ravn, I. H., \& Dahl, F. A. (2020). No Correlation Between Ethical Judgment in Trolley Dilemmas and Vaccine Scenarios for Nurse Specialist Students. Journal of Empirical Research on Human Research Ethics, 1556264620911234. https://doi.org/10.1177/1556264620911234

Patil, I., Zucchelli, M. M., Kool, W., Campbell, S., Fornasier, F., Calò, M., Silani, G., Cikara, M., \& Cushman, F. (2021). Reasoning supports utilitarian resolutions to moral dilemmas across diverse measures. Journal of Personality and Social Psychology, 120(2), 443-460.

https://doi.org/10.1037/pspp0000281 
Pettifor, A. (2020, January 16). BlackRock gets praise for coal divestment. What it really needs is regulation | Ann Pettifor. The Guardian.

https://www.theguardian.com/commentisfree/2020/jan/16/blackrock-coal-divestment-regulationfund-manager

Reynolds, C. J., \& Conway, P. (2018). Not just bad actions: Affective concern for bad outcomes contributes to moral condemnation of harm in moral dilemmas. Emotion, 18(7), 1009-1023. https://doi.org/10.1037/emo0000413

Riedl, A., \& Smeets, P. (2017). Why Do Investors Hold Socially Responsible Mutual Funds? The Journal of Finance, 72(6), 2505-2550. https://doi.org/10.1111/jofi.12547

The Economist. (2020, October 20). The generation game-Wall Street will soon have to take millennial investors seriously. The Economist. https://www.economist.com/finance-andeconomics/2020/10/20/wall-street-will-soon-have-to-take-millennial-investors-seriously

Trinks, P. J., \& Scholtens, B. (2017). The Opportunity Cost of Negative Screening in Socially Responsible Investing. Journal of Business Ethics, 140(2), 193-208. https://doi.org/10.1007/s10551015-2684-3

van Rooij, M., Lusardi, A., \& Alessie, R. (2011). Financial literacy and stock market participation. Journal of Financial Economics, 101(2), 449-472. https://doi.org/10.1016/j.jfineco.2011.03.006

Zingales, L. (2018, November 11). Public companies should prioritise shareholder welfare, not value. Financial Times. https://www.ft.com/content/52240e18-e412-11e8-a8a0-99b2e340ffeb 


\section{$\underline{\text { Electronic Supplementary Material (ESM1) }}$}

\section{Deontological and Utilitarian Responses to Sacrificial Dilemmas \\ Predict Disapproval of Sin Stocks}

\section{Stimuli}

\section{Study 1}

Participants rated the following statement (the industries were presented in random order):

Would it be morally appropriate if you invested in companies from the following industries? Please rate on a scale of 1 (not at all) to 7 (completely).

"Sin stocks" are "conventional stocks" where a list of industries used in Niszczota and Białek (2021). The former are a subset of 14 morally controversial industries used in Trinks and Scholtens (2017).

\section{$\underline{\text { Sin stocks }}$}

Abortion/Abortifacients. Companies owning or operating facilities where abortions are performed, abortion providers, abortifacient manufacturers.

Adult Entertainment. Companies targeted at the production or distribution of sexually explicit products and services, i.e., X-rated films, online products, production studios, printed materials, TV or radio programs, and adult clubs or bars.

Animal Testing. Companies that do research or perform tests on animals for medical and cosmetic reasons (to determine safety and efficacy of particular products).

Controversial Weapons. Companies involved in nuclear, biological, chemical weapons, cluster munitions, and antipersonnel mines.

Fur industry. Companies that manufacture, sell, or distribute fur products.

Gambling. Companies that manufacture, own, or operate gambling machines or equipment, casinos, lotteries and betting activities.

Tobacco. Companies involved in the production, processing and wholesale distribution of tobacco products.

\section{Conventional stocks}

Air Freight/Logistics. Companies providing air freight transportation, air courier, and air logistics services. 
Construction/Engineering. Companies engaged primarily in non-residential construction, as well as civil engineering companies.

Household Durables. Companies that manufacture consumer electronics, household appliances, houseware etc.

Marine. Companies providing maritime transportation of passengers or goods.

Road/Rail. Companies providing railroad and trucking transportation of passengers or goods.

Semiconductors/Semiconductor Equipment. Companies that manufacture semiconductors or semiconductor equipment.

Water Utilities. Companies that distribute water to consumers, also by being involved in water treatment. 


\section{Study 2}

We presented participants with two scenarios, either in the sin or non-sin (control) version [presented in italics]. After seeing each scenario (which were presented in random order), participants rated the following statement:

What is the likelihood that you would invest in this company?

Please rate on a scale of 1 (extremely unlikely) to 7 (extremely likely).

\section{$\underline{\text { Scenario } 1}$}

Imagine a company that was committed to environmentally friendly policies. Also, imagine that a new chief executive officer (CEO) had taken over the company, and planned to scrap the eco-friendly policies in favor of more profit planned [continue the eco-friendly policies].

\section{Scenario 2 (adapted from Bhattacharjee et al., 2017)}

Sigma Industries is a for-profit corporation that provides casual dining and catering services. Sigma is considering entering the market in a new region, which would involve changes to their current operations.

Because this market entry is an opportunity for Sigma to reevaluate its current practices, an executive at the firm has submitted a proposal recommending changes. Relative to the firm's current practices, this proposal involves reduced [continued] investment in socially responsible practices.

In particular, compared with Sigma's current practices, the proposal calls for lower [the same] levels of service quality, lower [higher] safety standards, and the use [continue avoiding] of potentially deceptive marketing practices. Under the new plan, Sigma would also decrease [continue increasing] employee pay and worsen [continue reducing] its impact on the environment.

Though Sigma's current practices are around overall industry average, the new proposal recommends practices that would be less [more] socially responsible than $82 \%$ of firms in the industry. 


\section{$\underline{\text { Study } 3}$}

Participants rated the following statement (the industries were presented in random order):

Would it be morally appropriate if you invested in companies from the following industries? Please rate on a scale of 1 (not at all) to 7 (completely).

"Sin stocks" where the same stocks that we used in Study 1. We used the following - alternative list of conventional stocks in this study:

Application Software. Companies engaged in developing and producing software designed for specialized applications for the business or consumer market. Includes enterprise and technical software.

Home Furnishings. Manufacturers of soft home furnishings or furniture, including upholstery, carpets and wall-coverings.

Life \& Health Insurance. Companies providing primarily life, disability, indemnity or supplemental health insurance.

Movies \& Entertainment. Companies that engage in producing and selling entertainment products and services, including companies engaged in the production, distribution and screening of movies and television shows, producers and distributors of music, entertainment theaters and sports teams.

Paper Packaging. Manufacturers of paper and cardboard containers and packaging.

Personal Products. Manufacturers of personal and beauty care products, including cosmetics and perfumes.

Research \& Consulting Services. Companies primarily providing research and consulting services to businesses and governments. Includes companies involved in management consulting services, architectural design, business information or scientific research, marketing, and testing \& certification services. 


\section{Studies 1 and 2}

\section{Self-rated investment knowledge item}

To what extent do you disagree or agree with the following statement below? Please rate on a scale of 1 (fully disagree) to 7 (fully agree):

My investment knowledge is good.

\section{Objective investment knowledge}

Items 1-4 were originally used in van Rooij et al. (2011). Items 5-6 were originally used in Agnew and Szykman (2005). The items were presented in random order. The minimum score in the investment knowledge test was 0 and the maximum was 6 .

1. Considering a long time period (e.g., 10 or 20 years), which asset normally gives the highest return: savings accounts, bonds or stocks?

2. Normally, which asset displays the highest fluctuations over time: savings accounts, bonds or stocks?

3. Stocks are normally riskier than bonds - is this statement True or False?

4. When an investor spreads money among different unrelated assets, does the risk of losing money: increase, decrease or stay the same?

5. If you were to invest $\$ 1000$ in a stock fund, would it be possible to have less than $\$ 1000$ when you decide to withdraw or move it to another fund?

6. High yield bond funds are invested in bonds with strong credit ratings - is this statement True or False?

\section{Risk tolerance item (Dohmen et al., 2012)}

How do you see yourself: are you generally a person who is fully prepared to take risks or do you try to avoid taking risks? Choose the appropriate number on a scale of 0 to 10 , where: $0=$ not at all willing to take risks, $10=$ very willing to take risks.

\section{Moral Judgment Task (Conway \& Gawronski, 2013)}

Participants were presented with ten moral dilemmas, each with two versions: congruent and incongruent. Incongruent dilemmas correspond to traditional high-conflict moral dilemmas (Koenigs et al., 2007), pitting deontology against utilitarianism. Congruent dilemmas are identically worded except for the benefits of harmful action in each dilemma, such that deontology and utilitarianism are no longer in conflict.

\section{Participant Instructions}

On the following screens you will see a series of short stories. Please read them carefully. Even though some stories may seem similar, each story is different in important ways. Please note that some stories refer to things that may seem unpleasant to think about. This is because we are interested in people's thoughts about difficult, real-life issues. If at any time you are uncomfortable, please stop participating in the study. 
After each story you will be asked to make a judgment about whether you find the action described appropriate or inappropriate. Using the mouse, click the button that best corresponds to your personal opinion. There is no right or wrong answer--just choose what seems best to you.

\section{Response Options and Coding}

Yes, I find this appropriate or No, I find this inappropriate

$1=$ Yes, I find this appropriate; $0=$ No, I find this inappropriate

\section{Order of Presentation}

$19,16,3,12,5,7,1,18,14,11,20,4,6,13,9,15,8,17,10,2$ 


\section{Incongruent Time Machine}

You find a time machine and travel back to the year 1920. While checking into a hotel, you meet a young Austrian artist and veteran of the First World War. You realize this is Adolf Hitler before his rise to power in Nazi Germany.

He is staying in the hotel room next to yours and the doors are not locked. It would be easy to simply smother him with a pillow in his sleep and disappear, stopping the Second World War and the Nazi party before they even start. However, he has not committed any crimes yet and it seems wrong to hurt an innocent person.

Is it appropriate for you to kill an innocent young Hitler in order to prevent the Second World War?

\section{Congruent Time Machine}

You find a time machine and travel back to the year 1920. While checking into a hotel, you meet a young petty criminal. You realize this is George Brackman, a man who later on abducted a child and held her for a week until her family paid him some ransom money.

He is staying in the hotel room next to yours and the doors are not locked. It would be easy to simply smother him with a pillow in his sleep and disappear, stopping the abduction and ransom demands before they even start. However, he has not committed any crimes yet and it seems wrong to hurt an innocent person.

Is it appropriate for you to kill George Brackman in order to prevent him from taking a child hostage? 


\section{Incongruent Car Accident}

You are driving through a busy city street when all of a sudden a young mother carrying a child trips and falls into the path of your vehicle. You are going too fast to brake in time; your only hope is to swerve out of the way.

Unfortunately, the only place you can swerve is currently occupied by a little old lady. If you swerve to avoid the young mother and baby, you will seriously injure or kill the old lady.

Is it appropriate to swerve and hit the old lady in order to avoid the young mother and child?
Is it appropriate for you to employ your daughter in the pornography industry in order to feed your family?

\section{Incongruent Hard Times}

You are the head of a poor household in a developing country. Your crops have failed for the second year in a row, and it appears that you have no way to feed your family. Your sons, ages eight and ten, are too young to go off to the city where there are jobs, but your daughter could fare better.

You know a man from your village who lives in the city and who makes sexually explicit films featuring girls such as your daughter. In front of your daughter, he tells you that in one year of working in his studio your daughter could earn enough money to keep your family fed for several growing seasons. 


\section{Congruent Car Accident}

You are driving through a busy city street when all of a sudden a young mother carrying a child trips and falls into the path of your vehicle. You are going too fast to brake in time; your only hope is to swerve out of the way.

Unfortunately, the only place you can swerve is currently occupied by a group of children on their way to elementary school. If you swerve to avoid the young mother and baby, you will seriously injure or kill several of them.

Is it appropriate to swerve and hit the schoolchildren in order to avoid the young mother and child?

\section{$\underline{6 \text { Congruent Hard Times }}$}

You are the head of a poor household in a developing country. Your sons, ages eight and ten, work on the family farm everyday in order to teach them the value of hard work and providing for others. Your daughter, however, cannot work on the farm due to the heavy lifting required. You worry that she will not learn the value of money if she does not work.

You know a man from your village who lives in the city and who makes sexually explicit films featuring girls such as your daughter. In front of your daughter, he tells you that in one year of working in his studio your daughter could earn enough money to keep your family fed for several growing seasons.
Is it appropriate for you to employ your daughter in the pornography industry in order to teach her the value of money? 


\section{Incongruent Crying Baby}

It is war time. Enemy soldiers have taken over your village. They have orders to kill all remaining civilians. You and some of your townspeople have sought refuge in the cellar of a large house. Outside you hear the voices of soldiers who have come to search the house for valuables.

A baby with no parents begins to cry loudly. You cover her mouth to block the sound. If you remove your hand from the baby's mouth her crying will summon the attention of the soldiers who will kill you and the others hiding out in the cellar. To save yourself and the others you must smother the child to death.

Is it appropriate for you to smother the child in order to save yourself and the other townspeople from being killed?

\section{Incongruent Relationship}

You are divorced now and your former spouse lives far away. You don't expect to see your former spouse for a very long time. However, you have recently started dating a new person that is positively wonderful. Your new partner is head over heels in love for the first time and you feel equally strong about your partner. You want to do everything in your power to keep the relationship progressing smoothly to what you believe will be a second marriage.

Unfortunately, your new partner has told you many times that dating someone who is divorced is totally unacceptable. It is expressly forbidden in your partner's religion. Your partner doesn't know about your ex-spouse. You consider simply pretending that you have never been divorced so that your current relationship can continue.
Is it appropriate for you to leave your new partner in the dark about your previous relationship in order to keep her/him happy and the relationship alive? 


\section{Congruent Crying Baby}

It is war time. Enemy soldiers have taken over your village. They have orders to capture all remaining civilians to make them work quarrying stone in a mine. You and some of your townspeople have sought refuge in the cellar of a large house. Outside you hear the voices of soldiers who have come to search the house for valuables.

A baby with no parents begins to cry loudly. You cover her mouth to block the sound. If you remove your hand from her mouth the crying will summon the attention of the soldiers who will capture you and the others hiding out in the cellar. To save yourself and the others from laboring in the mine you must smother the child to death.

Is it appropriate for you to smother the child in order to save yourself and the other townspeople from being captured?

\section{$\underline{10 \text { Congruent Relationship }}$}

You are divorced now and your former spouse lives far away. You don't expect to see your former spouse for a very long time. However, you have recently started dating a new person that is positively wonderful. Your new partner is head over heels in love for the first time and you feel equally strong about your partner. You want to do everything in your power to keep the relationship progressing smoothly to what you believe will be a second marriage.

Unfortunately, your ex-spouse gave you a very serious and incurable Sexually Transmitted Disease (STD). Your partner does not know about it. You consider simply pretending that you don't know about the STD so that your current relationship can continue.
Is it appropriate for you to leave your new partner in the dark about your STD in order to keep her/him happy and the relationship alive? 


\section{Incongruent Abortion}

You are a surgeon. A young woman you know becomes pregnant, but her body reacts in an unusual fashion. She develops a severe case of preeclampsia, a dangerous syndrome that leads to rapid increases in blood pressure. The only treatment is to deliver the baby.

Unless the baby is delivered soon, the mother will die. However, the baby is too young to survive on its own. If it is delivered, it will die. So, although it is very difficult for her, the mother asks you to abort the baby.

Is it appropriate for you to perform an abortion in order to save the mother's life?

\section{Incongruent Torture}

You are a police officer, and have recently caught a criminal you have been hunting for some time. He is allegedly responsible for rigging a series of explosive devices: some that have already gone off and some that have yet to detonate.

He places explosives outside city cafes and sets them to go off at a time when people are drinking coffee on the patios. In this manner, he has injured many people and might injure many more.

Now that the criminal is in custody, you want to know where the unexploded bombs are so you can defuse them. He refuses to talk, so you decide to use "aggressive interrogation techniques" like holding his head under water and beating him.
Is it appropriate for you to use "aggressive interrogation techniques" in order to find and defuse the unexploded bombs? 


\section{Congruent Abortion}

You are a surgeon. A young woman you know becomes pregnant, but she is not yet ready for children. She has not finished high school, has no income, and was abandoned by the father.

If she has the baby now, she will be stuck as a single mother on welfare for the rest of her life. This will make things very hard on her and the baby. She thinks that it would be smarter to wait and have children later. So, although it is very difficult for her, she asks you to abort the baby.

Is it appropriate for you to perform an abortion in order to let the mother live a better life?

\section{Congruent Torture}

You are a police officer, and have recently caught a criminal you have been hunting for some time. He is allegedly responsible for rigging a series of explosive devices: some that have already gone off and some that have yet to detonate.

He places explosives outside city cafes and sets them to go off at a time when no one is around. His explosives are inside paint cans so that they spray nearby objects with paint. In this manner, he has sprayed many cafes with paint and might spray many more.

Now that the criminal is in custody, you want to know where the unexploded bombs are so you can defuse them. He refuses to talk, so you decide to use "aggressive interrogation techniques" like holding his head under water and beating him.
Is it appropriate for you to use "aggressive interrogation techniques" in order to find and defuse the unexploded bombs? 


\section{Incongruent Vaccine Policy}

You are a doctor in a health clinic overrun by patients with a serious disease. You just received a shipment of drugs that can cure the disease but the drugs have their own severe side-effects.

If you administer the drugs to your patients, a small number will die from the side effects but most will live. If you do not, most will die from the disease.

Is it appropriate for you to administer the drug to your patients?

\section{Incongruent Animal Research}

You have been hired by a pharmaceutical company to conduct research on their products. Since products must be fit for human use, they are first tried out on animals. Your job is to find out the effects various chemicals have on rats, pigeons, rabbits, and monkeys. Most chemicals have only minor effects on the animals, but some cause them discomfort or even permanent damage.

The chemicals you are researching are slated to form part of a new AIDS drug cocktail that will give new hope to millions of AIDS victims around the world. You anticipate saving many lives with the chemicals.

Is it appropriate to test these chemicals on animals?

\section{$\underline{16 \text { Congruent Vaccine Policy }}$}

You are a doctor in a health clinic overrun by patients with the latest flu virus. You just received a shipment of drugs that can cure the flu but the drugs have their own severe sideeffects.

If you administer the drugs to your patients, a small number will die from the side effects but most will live. If you do not, most will continue to suffer from the effects of the flu virus for some time.

Is it appropriate for you to administer the drug to your patients?

\section{Congruent Animal Research}

You have been hired by a pharmaceutical company to conduct research on their products. Since products must be fit for human use, they are first tried out on animals. Your job is to find out the effects various chemicals have on rats, pigeons, rabbits, and monkeys. Most chemicals have only minor effects on the animals, but some cause them discomfort or even permanent damage.

The chemicals you are researching are slated to form part of a new acne facial cleanser that will give new hope to people with pimples and greasy skin. You anticipate making many people feel better about their appearance with the chemicals.

Is it appropriate to test these chemicals on animals? 


\section{Incongruent Border Crossing}

You are a soldier guarding a border checkpoint between your nation and one troubled by insurgent violence. You notice a young man in a cheap car approaching the checkpoint with a determined look on his face.

You suspect he means to bomb the checkpoint, killing all the soldiers inside. He is rapidly approaching your station.

Is it appropriate for you to shoot and kill the approaching man?

\section{Congruent Border Crossing}

You are a soldier guarding a border checkpoint between your nation and one troubled by insurgent violence. You notice a young man in a cheap car approaching the checkpoint with a determined look on his face.

You suspect he means to cross the border in order to work illegally inside your country. He is rapidly approaching your station.

Is it appropriate for you to shoot and kill the approaching man? 


\section{References}

Agnew, J. R., \& Szykman, L. R. (2005). Asset Allocation and Information Overload: The Influence of Information Display, Asset Choice, and Investor Experience. Journal of Behavioral Finance, 6(2), 57-70. https://doi.org/10.1207/s15427579jpfm0602_2

Bhattacharjee, A., Dana, J., \& Baron, J. (2017). Anti-profit beliefs: How people neglect the societal benefits of profit. Journal of Personality and Social Psychology, 113(5), 671-696. https://doi.org/10.1037/pspa0000093

Conway, P., \& Gawronski, B. (2013). Deontological and utilitarian inclinations in moral decision making: A process dissociation approach. Journal of Personality and Social Psychology, 104(2), 216-235. https://doi.org/10.1037/a0031021

Dohmen, T., Falk, A., Huffman, D., \& Sunde, U. (2012). The Intergenerational Transmission of Risk and Trust Attitudes. The Review of Economic Studies, 79(2), 645-677. https://doi.org/10.1093/restud/rdr027

Koenigs, M., Young, L., Adolphs, R., Tranel, D., Cushman, F., Hauser, M., \& Damasio, A. (2007). Damage to the prefrontal cortex increases utilitarian moral judgements. Nature, 446(7138), 908.

https://doi.org/10.1038/nature05631

Niszczota, P., \& Białek, M. (2021). Women oppose sin stocks more than men do. Finance Research Letters, 41, 101803. https://doi.org/10.1016/j.frl.2020.101803

Trinks, P. J., \& Scholtens, B. (2017). The Opportunity Cost of Negative Screening in Socially Responsible Investing. Journal of Business Ethics, 140(2), 193-208. https://doi.org/10.1007/s10551-015-2684-3

van Rooij, M., Lusardi, A., \& Alessie, R. (2011). Financial literacy and stock market participation. Journal of Financial Economics, 101(2), 449-472. https://doi.org/10.1016/j.jfineco.2011.03.006 
Electronic Supplementary Material (ESM2)

Deontological and Utilitarian Responses to Sacrificial Dilemmas Predict Disapproval of Sin Stocks

Supplementary Figures and Tables 
Study 1

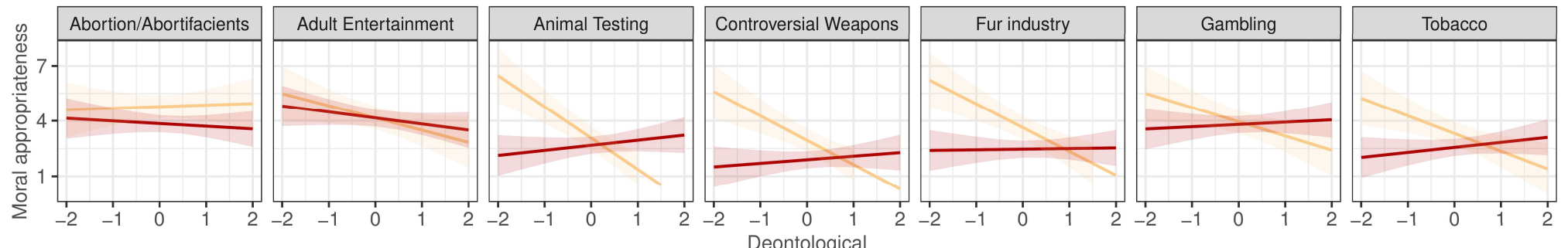

Study 2
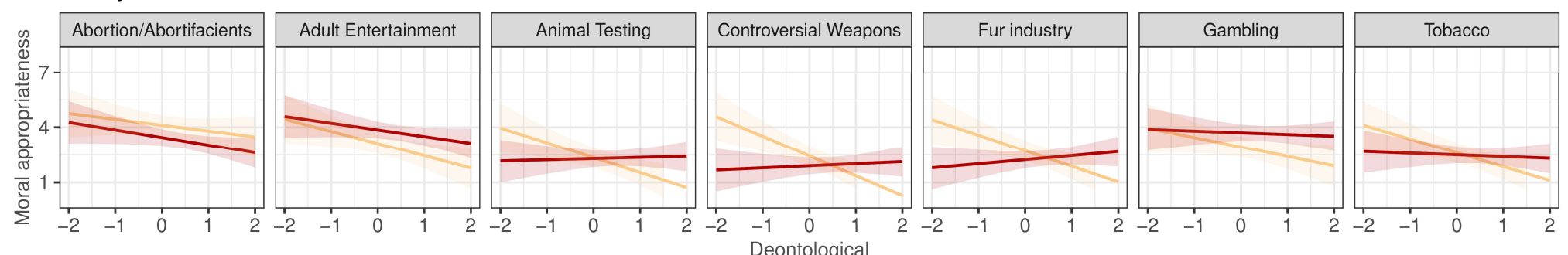

Study 3
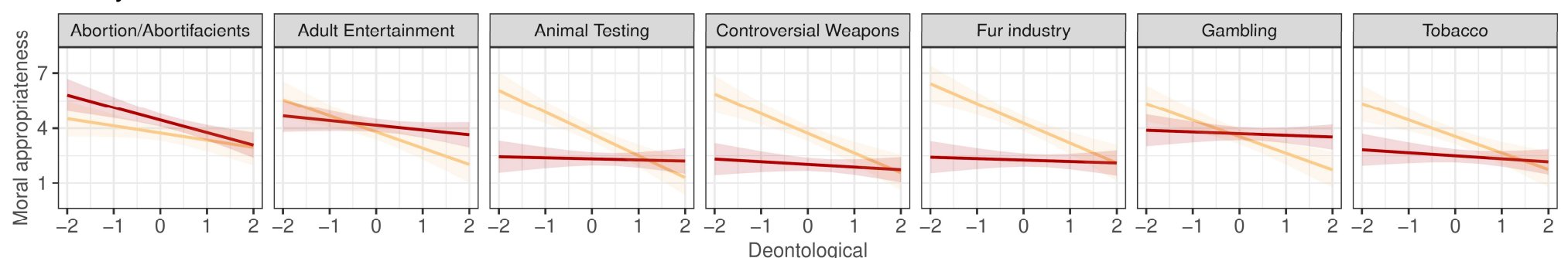

Studies 1-3 pooled
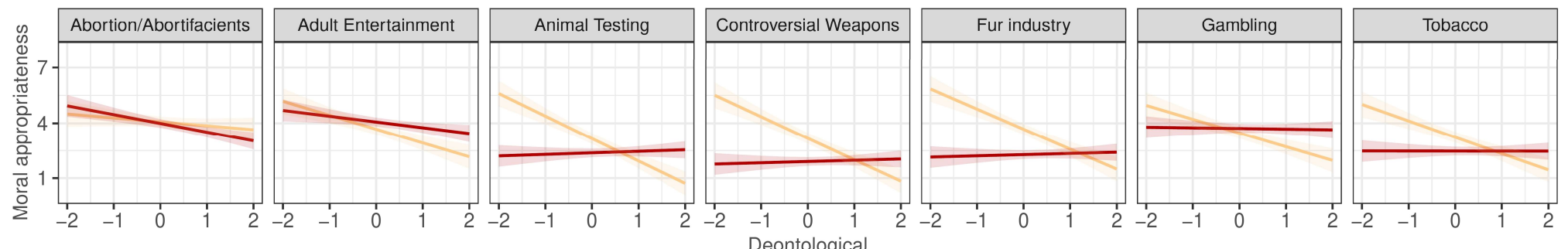

Utilitarian $\quad-2 \boxminus 2$ 
Figure S1. The interaction between standardized deontological and utilitarian response tendencies in sacrificial dilemmas and moral evaluations of investing in sin stocks. Effects plotted for the low $(-2 S D)$ and high $(+2 S D)$ utilitarian inclinations. Error bars represent $95 \%$ confidence intervals. 


\section{Study 1}
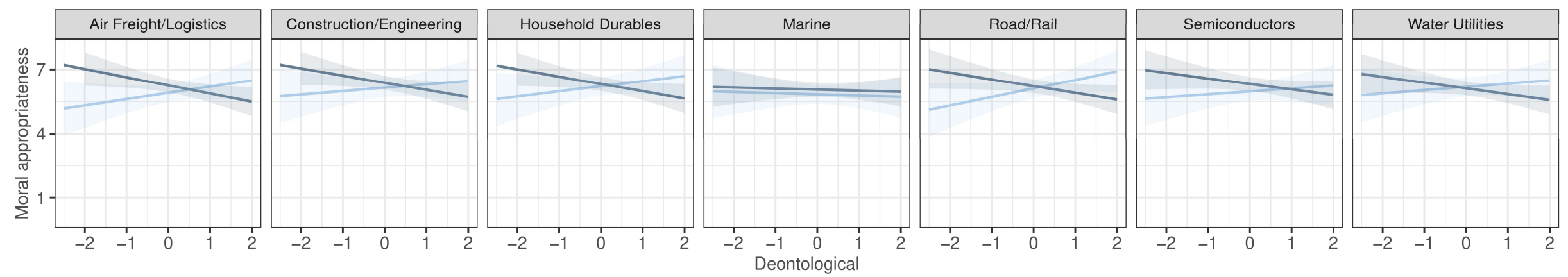

\section{Study 2}
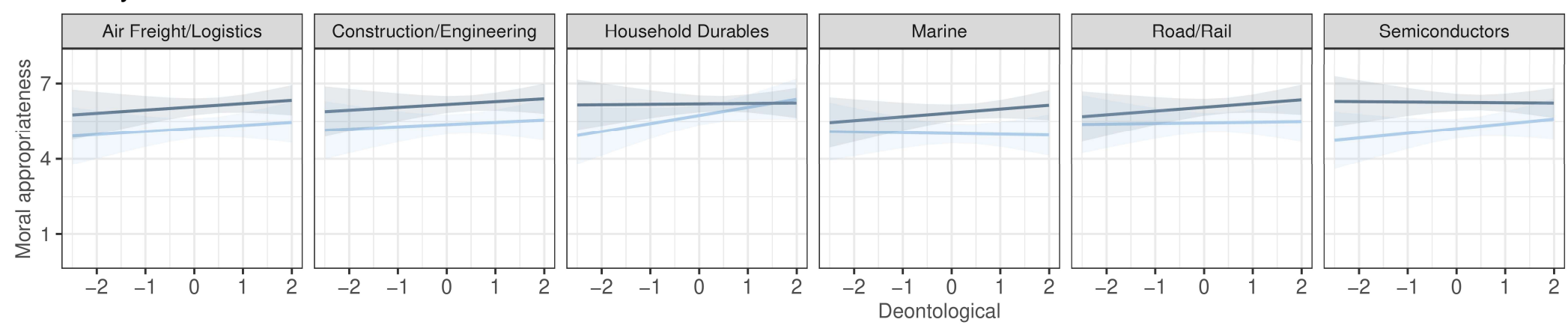

Water Utilities

\section{Study 3}
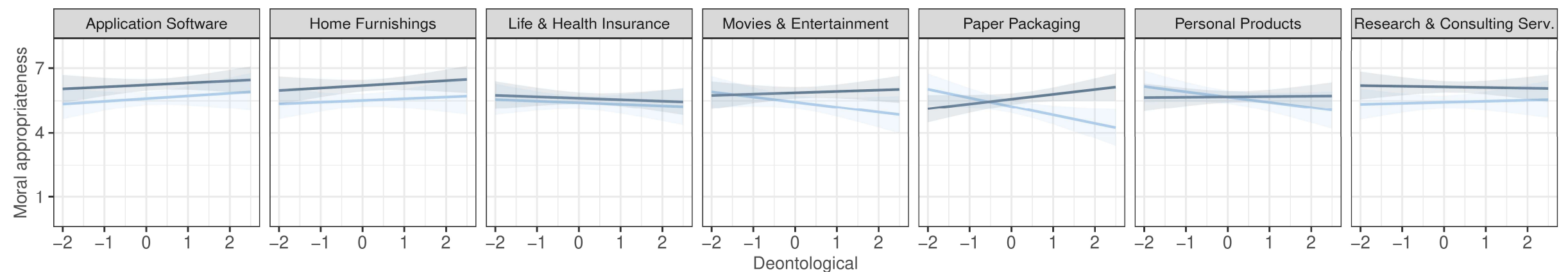

Utilitarian $\square-2 \square 2$ 
Figure S2. The interaction between standardized deontological and utilitarian response tendencies in sacrificial dilemmas and moral evaluations of investing in conventional stocks. Effects plotted for the low $(-2 S D)$ and high $(+2 S D)$ utilitarian inclinations. Error bars represent $95 \%$ confidence intervals. 
Table S1. Comparison of societal contribution of original and alternative set of conventional stocks

\begin{tabular}{lcc}
\hline & $\boldsymbol{M}$ & $\boldsymbol{S D}$ \\
\hline Water Utilities & 4.41 & 0.89 \\
Construction/Engineering & 4.34 & 0.86 \\
Road/Rail & 4.21 & 0.95 \\
Semiconductors/Semiconductor Equipment & 4.12 & 0.98 \\
Household Durables & 4.11 & 0.91 \\
Air Freight/Logistics & 4.10 & 1.03 \\
Application Software & 4.08 & 1.03 \\
Marine & 3.97 & 1.06 \\
Home Furnishings & 3.95 & 0.94 \\
Life \& Health Insurance & 3.88 & 1.14 \\
Research \& Consulting Services & 3.85 & 0.98 \\
Personal Products & 3.75 & 1.03 \\
Paper Packaging & 3.79 & 1.02 \\
Movies \& Entertainment & 3.76 & 1.08 \\
\hline
\end{tabular}

Note: This table reports the results of a pilot study for Study $3(N=131)$, in which MTurk workers rated the statement "What do you think about the value of companies from these industries to society, on the whole?" on a scale of 1 (it would be better if they would not exist) to 5 (they are important and useful). Alternative conventional stocks are indicated in bold. A $t$-test suggested that the alternative set of sin stocks was rated less favorably than the original set of conventional stocks $\left(M_{\text {original }}=4.18, S D=0.72, M_{\text {alternative }}=3.86, S D=0.68\right.$, $\left.t_{\text {paired }}=6.28, p<.001\right)$. 